\title{
Una mirada a la transparencia informativa institucional a través de los Social Media
}

Information transparency in the social media communications of public institutions

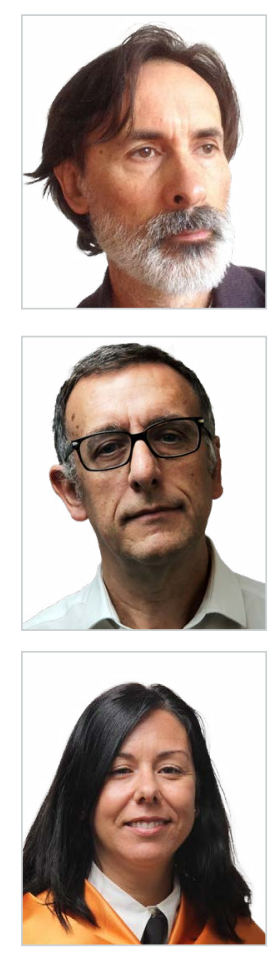

Jesús Gutiérrez Brito. Doctor en Sociología por la Universidad Complutense de Madrid. Actualmente es profesor titular de Métodos y Técnicas de investigación social, y Coordinador del Máster en Comunicación, Cultura, Sociedad y Política en la Facultad de CC. Políticas y Sociología de la Universidad Nacional de Educación a Distancia. En el ámbito académico, ha desarrollado investigación sobre el vínculo social grupal, donde a su vez ha llevado a cabo estudios sobre la aplicación práctica de las técnicas de investigación social, en especial del grupo de discusión (Dinámica del Grupo de Discusión, CIS) para el estudio de la demanda y la recepción.

Universidad Nacional de Educación a Distancia (UNED), España

jgutierrez@poli.uned.es

ORCID: 0000-0003-1260-0831

Manuel Javier Callejo Gallego. Doctor en Sociología y licenciado en Sociología, Ciencias de la Información y Derecho por la Universidad Complutense. Actualmente es Catedrático de Sociología de la Universidad Nacional de Educación a Distancia, donde imparte Técnicas de investigación social y Sociología de la Comunicación. Entre 2010 y 2012 fue director del Departamento de Investigación del Centro de Investigaciones Sociológicas. Ha desarrollado investigación en diversos temas como el consumo, el análisis de la recepción en comunicación y el uso de las nuevas tecnologías. Universidad Nacional de Educación a Distancia (UNED), España mcallejo@poli.uned.es ORCID: 0000-0002-0856-5642

Yolanda Agudo Arroyo. Doctora en Sociología por la Universidad Nacional de Educación a Distancia. Actualmente, profesora titular del Departamento de Teoría, Metodología y Cambio Social de la Facultad de Ciencias Políticas y Sociología de la UNED. Combina su docencia en Sociología de la Educación, Métodos y Técnicas de Investigación y Género y Medios de Comunicación, con investigaciones sobre los vínculos entre la educación superior y el empleo desde la perspectiva de género, sobre la sociología de la comunicación, sobre la metodología de la educación a distancia y sobre metodología de la investigación.

Universidad Nacional de Educación a Distancia (UNED), España

yagudo@poli.uned.es

ORCID: 0000-0002-6185-0899

Recibido: 21/06/2021 - Aceptado: 10/11/2021 - En edición: 15/12/2021 - Publicado: 01/01/2022

\section{Resumen:}

Este trabajo es parte de una investigación empírica que tiene por objeto explorar la participación ciudadana en la consecución de la transparencia informativa institucional a través de los social media. A partir de un estudio de corte cualitativo, utilizando grupos de discusión, se
Received:21/06/2021 - Accepted: 10/11/2021 - Early access: 15/12/2021 - Published: 01/01/2022

\section{Abstract:}

This article is part of an empirical study on citizen participation in institutional information transparency on social media. Based on a qualitative design and the use of discussion groups, the research analyses the phenomenon of 'receiver transparency' grounded in the

Cómo citar este artículo:

Gutiérrez Brito, J., Callejo Gallego, M. C. y Agudo Arroyo, Y. (2022). Una mirada a la transparencia informativa institucional a través de los Social Media. Doxa Comunicación, 34, pp. 103-120.

https://doi.org/10.31921/doxacom.n34a903 
indaga y analiza la existencia de una "transparencia receptora" fundamentada en los presupuestos de una fenomenología del ámbito escópico y la concepción de la mirada que formula la teoría lacaniana. Las conclusiones del trabajo discuten y matizan la idea genérica que relaciona indefectiblemente el grado creciente de accesibilidad a la información con la producción efectiva de transparencia en la ciudadanía, especialmente si se tiene en cuenta las deficiencias en las que incurre el emisor al comunicar información inaccesible y/o limitada desde el punto de vista del receptor. Sobre este particular, el trabajo platea una tipología de transparencias informativas y en especial la emergencia de una "transparencia verosímil" vinculada al papel activo del ciudadano cuando la información a la que accede es incoherente o no cumple cabalmente con la información que se demanda.

\section{Palabras clave:}

Transparencia informativa; social media; comunicación; estudio cualitativo; instituciones públicas; participación ciudadana; recepción. premises of visual phenomenology and the concept of the 'gaze' from Lacanian theory. The conclusions of the study discuss and critically assess the prevailing idea that the increasing accessibility of information equates to the effective production of transparency and its endorsement by citizens. Of particular concern are shortcomings in communications issued by institutions that are inaccessible or limited from the perspective of citizens (receivers). The analysis leads to a proposal for a typology of information transparency, including a 'credible transparency' related to the active role of citizens when the information they receive is incoherent or does not comply with the information demanded.

\section{Keywords:}

Informational transparency; social media; communication; qualitative research; public institutions; citizen participation; reception.

\section{Presentación}

El avance de la transparencia informativa aparece en las sociedades democráticas como una cuestión de interés para el desarrollo de la ciudadanía y el papel político del aparato administrativo del Estado, y de las restantes instituciones sociales ${ }^{1}$. Ello se debe no sólo al efecto legitimador de la participación para el sistema político que promociona la transparencia, sino también para la misma sociedad de la información (el mundo Internet) que aparece como depositaria de la mayor capacidad de información y comunicación horizontal que jamás se haya experimentado. En este entorno tan propicio, se plantea traer los resultados empíricos de un estudio cualitativo ${ }^{2}$ sobre la importancia de la comunicación virtual para la producción de la transparencia informativa desde un punto de vista social, con especial interés en conocer el papel activo (participativo) del ciudadano en dicho proceso formativo . $^{3}$

Se prescinde, por tanto, de la idea de transparencia informativa que la misma organización institucional, ya sea pública o privada, ha desarrollado como efecto del cumplimiento de las disposiciones jurídico - legales y con el fin de garantizar por ley su existencia. Por el contrario, el interés de este trabajo parte de la importancia que tiene la dimensión comunicativa para la concreción del

1 Fung (2013) mantiene que la transparencia democrática implica cuatro pasos sucesivos, todos ellos relacionados con la información: información divulgativa, calidad de la información, acceso a la información y uso de la información.

2 Este estudio fue realizado gracias a las Ayudas de Acciones de Promoción de la Transparencia u Acceso a la información Pública (2016). Entre otros objetivos, la principal acción investigadora se dirigía a establecer la relación entre transparencia de la Administración Pública Española y un canal o medio de comunicación actual como son las redes sociales que se despliegan en el "mundo Internet".

3 Con las redes sociales en Internet, parecen quedar lejos los tiempos en los que la transparencia quedaba concretada como libertad de prensa e incluso como acceso a la información (archivos, documentos, datos, especialmente bajo el impulso del movimiento Open Data), caminándose hacia una transparencia más activa (Lathrop y Ruma, 2010). 
fenómeno de la transparencia desde el punto de vista de la recepción, así como la incidencia que tiene en los medios de comunicación de masas, y muy especialmente en el uso de redes y comunidades sociales virtuales.

En concreto, el estudio explora distintos tipos de transparencia y de participación ciudadana con la intención de refutar y matizar la idea genérica que relaciona el grado creciente de accesibilidad a la información con la producción efectiva de dicha transparencia y su asentimiento (Unsworth y Townes, 2012; McDermott, 2010). Desde el punto de vista del estudio realizado, la supuesta accesibilidad referida debe ser completada, incluso relacionada con la posibilidad de incluir también información inaccesible en la producción de la pretendida transparencia ${ }^{4}$.

\section{Planteamiento teórico y enfoque metodológico del estudio}

En general, desde un punto de vista teórico, la transparencia informativa es plateada desde el emisor que la produce y la gestiona unilateralmente. Es decir, que la puesta en escena, el proceso por el cual la información es mostrada y expuesta a otros (reales o potenciales), es resultado de entender la comunicación como un proceso automático y eficiente en el que la información está garantizada por la necesaria correspondencia entre emisores y receptores. En este sentido cabe entender el vínculo entre transparencia y apertura comunicativa hacia el público. Tal como menciona la Guía de lenguaje claro de la ONG Transparencia Internacional (2009: 48), la transparencia se define como:

“[La] cualidad de un gobierno, empresa o persona de ser abierta en la divulgación de información, normas, planes, procesos y acciones. Como regla general, los funcionarios, gerentes, directores de empresas y organizaciones y las juntas directivas tienen la obligación de actuar de manera visible, predecible y comprensible en la promoción de la participación y la rendición de cuentas".

En la misma línea, La Organización para la Cooperación y el Desarrollo Económicos (OCDE), en diversos informes y recomendaciones también entiende la transparencia como el entorno en el que los objetivos políticos, su marco, la justificación de las decisiones políticas, datos e información relacionados con los soportes económicos de las políticas, son ofrecidos al público en una manera comprensible, accesible y oportuna.

Ahora bien, este amplio planteamiento ajustado a estándares y procedimientos, y que entiende la comunicación como un producto ininterrumpido e inequívoco, no está libre de distorsiones e impedimentos para el caso concreto de la transparencia informativa. En concreto tiende a omitirse en este planteamiento la parte de comprensión e interpretación que surge por defecto para todo acto comunicativo.

Es decir, desde el punto de vista de la comunicación humana, la recepción de la información es una dimensión aparte e independiente de la estancia emisora. Por este motivo, el análisis que ofrece este trabajo tiene como primer objetivo poner a prueba esta distinción (separación) entre una transparencia vinculada al emisor y otra vinculada al receptor y sin garantía alguna de correspondencia entre ambas.

4 No se puede dejar pasar la ocasión para señalar que las redes sociales en Internet han contribuido a generar una mayor transparencia (Austin y Upton, 2016), incluso "supertransparencia" en contra de los esfuerzos que hacen las organizaciones por mantener cierta información fuera del espacio público. En cierta forma, esta observación ya alienta el supuesto de una posible accesibilidad a la información inaccesible. 
Sobre la primera (transparencia emisora) se encuentran análisis y teorías que tratan la información como un producto a mostrar sin mayor interés por especificar el papel de la recepción (transparencia receptora), la cual es considerada sobreañadida y supuestamente atenta a la emisión de información para su conocimiento.

La teoría del secreto que desarrolla Simmel (1906) en torno a lo que es conocido y, por tanto, compartido por unos u otros, responde a este planteamiento que privilegia al emisor y su información en detrimento de un receptor que queda a expensas de que otros (emisores) compartan cierta información.

También la teoría de la visión que desarrollan autores clásicos como Bentham (1979) con la concepción del panóptico, y que retoman de diversa manera autores posteriores como Foucault, (1986), Vattimo, G. ( 1989), Wajcman, G. (2010) o Byung-Chul Han (2014), estarían dentro de esta concepción "emisora" donde la visión, lo que se puede ver es lo que otros dejan entrever, dependiendo claramente de aquello que es posible o se quiere mostrar. De ahí que la posibilidad de la ocultación sea una cuestión central y anterior, y que afecte a un escenario donde algo queda a la vista y mucho antes de que se produzca la complejidad de un ojo que escrute o vigile.

En síntesis, desde el punto de vista emisor, la transparencia permite al ojo "ver" pero no "mirar". Es decir, la opacidad se genera precisamente en la mostración o puesta a la vista sin contar con la intencionalidad de un ojo escrutador que pretende ver (mirar) algo $^{5}$. Dicha opacidad, consecuente con su interés para evitar la ocultación, lo que estaría descartando sería la vigilancia manifiesta en la recepción. Si la transparencia emisora evita la ocultación de información poniéndola a la vista (generando supervisión), la transparencia receptora la reclama por cercenar su interés en mirar más allá de lo visto y expuesto.

Por otro lado, estirando la teoría simeliana a las apreciaciones anteriores, el secreto y la misma información revelada a otros aparece como cara y cruz de la misma moneda. Aquello que no es secreto es por ello revelado y, por tanto, manifiesto o desvelado automáticamente. De manera que, en la transparencia informativa hay indefectiblemente una parte positiva y otra negativa estrechamente relacionadas ${ }^{6}$. La positiva es igualitaria porque el acento se pone en la parte convergente donde emisor y receptor encuentran cierta información compartida; mientras que la negativa es divergente por mantener a su vez cierta ocultación diferenciadora sobre la información revelada. Sin embargo, el hecho de que ambos tipos de transparencias se requieran entre sí, implica que la transparencia igualitaria tenga como horizonte un mínimo de divergencia entre la información revelada (emitida) y la información recabada (recibida). Dicho con otras palabras, cuanta más transparencia (revelación) menos puede mirar (informarse) el receptor, hasta el punto paradójico de llegar a identificar la transparencia con la "invisibilidad” y, por tanto, con la ocultación que la misma transparencia pretende erradicar.

El trabajo que se presenta ha querido mostrar en el análisis la relevancia que tiene una "transparencia negativa" que se produce con la existencia de cierta información a la que no tiene acceso el receptor salvo por la parte que escatima u oculta el emisor (la sospecha).

5 En este sentido, los medios de comunicación -incluidas las redes sociales- son dispositivos centrales en la producción de transparencia, así como de intransparencia. Tal como refiere Luhmann (2000: 147): “El efecto parece consistir en la reproducción de intransparencia mediante transparencia: reproducción de intransparencia de efecto, mediante transparencia de conocimiento".

6 Esta diferencia parte de la idea de una sociedad positiva (expuesta) y otra negativa (velada) Byung-Chul Han (2014). 
Es decir, se plantea introducir para este análisis un planteamiento teórico que permita entender la visión de información allí donde no hay demostración efectiva por diversos motivos (mala visión, desconocimiento de los códigos por parte del receptor, confusión en los mensajes o canales de comunicación, etc.).

Dicho planteamiento se encuentra implícito en la idea de mirada que formula la teoría lacaniana (Lacan, 1964) y en los presupuestos de una fenomenología del ámbito escópico (Merleau - Ponty, 1986), que distingue claramente entre "ver" y "mirar" el mundo que nos rodea. Muy sintéticamente, bajo estos supuestos teóricos, la mirada no es un punto de encuentro y/o de correspondencia entre lo visible (mostrado) y lo visto por un sujeto. Más bien es todo lo contrario; es decir, la mirada surge de la "mancha" que impide la transparencia de la imagen puesta a la vista. En este sentido, Zizek (2000), refiriéndose al cine, señala la insuficiente intención de la cámara cuando muestra lo que vemos, ya que sólo vemos fragmentos de un todo supuestamente evidente y completo. Sin embargo, lo que no vemos es lo que suscita el deseo de ver y lo que potencia la mirada del espectador (receptor). De la misma manera, todo ejercicio de la transparencia es un ejercicio forzosamente artificioso e incompleto de mostrar información al ciudadano, pero en dicho intento de hacer visible dicha información se pone en juego la recepción según la información 1.- suscite cierta actitud pasiva en el receptor o que, por el contrario, 2.- se convierta en motivo de participación en la consecución de información parcial que se le presenta como engañosamente evidente y completa.

A partir de este enfoque teórico, la investigación que se presenta consideró necesario explorar hasta qué punto los ciudadanos entienden como ejercicio de transparencia las variadas actuaciones informativas en las redes sociales digitales de diversas instituciones españolas (públicas y privadas). Para ello, se realización tres grupos de discusión entre usuarios habituales de redes sociales. La opción por esta práctica de investigación cualitativa viene dada por la intención de responder al requerimiento de la investigación desde los marcos ideológicos de los usuarios, de manera que la relación entre redes sociales digitales institucionales y la transparencia informativa surgiera espontáneamente, y no de la sugerencia para encontrar dicha relación en un interés concreto por parte las instituciones. Con este propósito se diseñaron tres grupos de discusión, con los siguientes perfiles ${ }^{7}$ :

- Reunión de grupo 1: Jóvenes entre 25 y 30 años, de clases media-media y media-alta. Con estudios universitarios y, al menos la mitad, ocupados en empresas del sector privado y desempeñando puestos técnicos (los verbatims de esta reunión de grupo quedan referidos como RG1).

- Reunión de grupo 2: Hombres entre 30 y 40 años, de clases medias y ocupados (empleados en sector servicios: sector financiero, seguros, comercio...) (RG2).

- Reunión de grupo 3: Mujeres entre 30 y 40 años, de clases populares. La mitad, al menos, mujeres ocupadas desempañando labores comerciales y administrativas (RG3).

Todos los grupos tuvieron lugar en Madrid en 2017, y como condición general a los/las participantes se les exigió que fueran usuarios activos de Twitter o Facebook. Aun cuando la lógica cualitativa de esta práctica de investigación está dominada por la apertura y no directividad de los grupos, se partió del siguiente orden de cuestiones a recabar:

7 Los grupos de discusión responden a un diseño estructural que metodológicamente no tiene en cuenta la representatividad estadística. Son muestras intencionales elaboradas a partir de criterios sociodemográficos y de interés para el objeto de estudio, y en función de los potenciales nichos discursivos que presenta la estructura social. En el caso de esta investigación, los criterios han sido la edad (jóvenes, mayores), el sexo (mujeres, hombres), el nivel de estudios (medios y superiores) y el uso activo (uso diario) de las redes sociales (Twitter y Facebook). 
- Uso habitual de las redes sociales digitales: motivaciones, resistencias, argumentos, etc.

- Actividades que han dejado de hacerse o que se hacen menos, de manera que tal cambio pudiera atribuirse al mayor uso de las redes sociales. Especialmente dirigido a sondear la menor relación con los medios de comunicación.

- Cuentas no personales de redes sociales digitales que se siguen. Razones para el seguimiento.

- Presentación a los participantes de una pequeña muestra de mensajes en redes sociales de cuentas instituciones: empresas, instituciones públicas, organismos, etc.

- Presentación de mensajes en redes sociales de instituciones de la Administración Central del Estado.

- Conocimiento y opinión sobre Ley de Transparencia.

- Percepción de la vinculación entre transparencia y uso de las redes sociales digitales por parte de las instituciones.

Por último, la muestra de estímulos utilizados (tuits) procede del rastreo de algo más de 150 cuentas de distintas instituciones de la Administración Central del Estado, repartidas entre Facebook (57 cuentas) y Twitter (90 cuentas). Para las capturas se utilizó el software Ncapture de NVivo. La selección de los estímulos, casi 40.000 tuits recabados entre el 1 de febrero y 21 de marzo de 2017, se hizo intencionadamente y teniendo en cuenta la diversidad de mensajes capturados (aspectos estéticos y de contenido). El resultado de dicha selección fue la construcción de un corpus de 67 tuits procedentes de diferentes organismos y con una variedad lo más extensa posible.

\section{Revelación y compartición de información en los Social Media}

En la introducción ya se ha señalado la idea de una transparencia informativa y su función legitimadora en las sociedades democráticas. Son numerosos los estudios en los que se vincula las nuevas tecnologías ofreciendo sus potencialidades a la ciudadanía, facilitando la interacción entre las instituciones del Estado y la sociedad civil (Subirats, 2012; Villoria y Ramírez, 2013). En la misma línea cabe apuntar los estudios centrados en la presencia y desarrollo del concepto de Gobierno Electrónico (Gil-García y Catarrivas, 2017; Layne y Lee, 2001; Backus, 2002) para generar mecanismos de acceso a la información pública y a la participación ciudadana. Ahora bien, este interés vinculado al desarrollo de las nuevas tecnologías no parece tan decisivo como el hecho comunicativo que afecta al aporte de la información.

A continuación, se precisa en qué sentido el acceso a la información presupone a su vez una restricción en los grupos de discusión realizados, y cuáles son los determinantes que posibilitan o restringen dicho acceso desde un punto de vista comunicacional. Para ello es necesario tener en cuenta que la transparencia, en tanto ideal democrático, tiene por objeto compartir toda aquella información (pública o privada) que compete y/o afecta al funcionamiento del sistema democrático en su conjunto y muy especialmente a sus instituciones u organismos afectados. Ahora bien, en realidad la compartición de toda la información susceptible de ser comunicada es siempre parcial y/o limitada, ya que compromete a su vez el derecho que tienen otros (individuos, grupos, instituciones u organismos) a no revelar ni compartir cierta información por diversos motivos. Se trata de poner en conocimiento información que normalmente se considera privada en un sentido amplio, pero que en otras circunstancias podría ser simplemente no adecuada o no pertinente por cortesía, por prudencia, por evitar la confrontación o el conflicto, la sobre información, etc. 
De este modo, tal como señala la teoría simmeliana, de cara a la transparencia toda información estaría doblemente limitada o restringida en términos de comunicación:

a) Por la compartición (transmisión) en referencia al acceso a información y las diferencias sociales que esto produce entre grupos e individuos en función del grado de propagación o difusión. Es decir, estrategias -públicas y privadas- que se ven respaldadas por el relativo bajo coste económico de la transparencia, especialmente cuando queda reducida a difusión de información (Kaufman y Siegelbaum, 1997; Hellman y Kaufman, 2001).

b) Por la revelación que atenta contra las normas de convivencia y que imponen salvaguardar o excluir cierta información para mantener viva la relación y la misma comunicación sobre la que se sustenta.

Considerándose estos presupuestos en los grupos realizados, y con el fin de obtener respuestas espontáneas sobre el papel informativo de la transparencia en los social media, fueron seleccionados aleatoriamente un amplio repertorio de tuits procedentes de diferentes instituciones gubernamentales y de empresas públicas con el objeto de observar la recepción de la información emitida. Dicha selección tenía por objeto recoger la mayor variedad de mensajes en función de los diversos contenidos y estilos empleados entre las distintas instituciones testadas. Para evitar influencias entre estímulos, dicho repertorio fue mostrado a los grupos en distinto orden y provocar así el discurso espontáneo en atención al surgimiento de la transparencia informativa y su posible percepción / valoración.

Las respuestas espontáneas en los tres grupos fueron muy limitadas y similares entre sí. Sobre la cuestión del interés informativo se observó un escaso seguimiento de organismos o instituciones, ya sean públicas o privadas. No obstante, al margen de esta pobreza de manifestaciones espontáneas, es relevante señalar excepciones destacadas como el seguimiento de la administración local (ayuntamientos del lugar de residencia), la Policía Nacional o la Dirección General de Tráfico.

Por otro lado, la actitud general hacia los tuits presentados fue positiva en general y a pesar de la desconfianza que generaron algunos estímulos entre los participantes, especialmente cuando procedían de empresas o negocios bancarios relacionados con las finanzas. En cualquier caso, las dinámicas generadas disculpaban la ausencia de una mayor información en los tuits presentados por el interés de evitar temas censurables como la corrupción o los problemas con la justicia, la legalidad, etc. Aunque a priori la información limitada se podría considerar una falta de transparencia por cuestiones como el empleo del dinero público, el interés particular de los poderosos o la falta de procedimientos adecuados y justos, etc., en general los grupos comparten la idea de que "una cosa es que te lo digan y otra lo que te imaginas".

Se apunta de este modo a una dimensión, la implícita y/o presupuesta, que afecta a la información de los tuits mostrados y a la observación de la transparencia tal como este trabajo conceptualiza con la inclusión de la parte receptora completando y transformado el mensaje emisor.

Teniendo en cuanta esta apreciación general, la existencia de los tuits y su información no parece tener tanta importancia como lo que dichos mensajes provocan en las muestras para introducir algún comentario irónico o tema aledaño que complementa o matiza dicha información. Atendiendo a esta impronta, las reacciones provocadas en los grupos nos permiten agrupar los tuits en tres categorías definitorias para la transparencia y su aporte informativo en términos de visibilidad: tuits previsibles, tuits visibles y tuits invisibles. Se comenta esta tipología a partir de las reacciones que provocaron: 


\section{Tuits previsibles}

Se incluyen aquí algunos tuits referidos al Ministerio de Interior, Ministerio de Economía, Ministerio de Exteriores, Biblioteca Nacional, etc. El siguiente ejemplo se incluye en este tipo de tuits previsibles:

\section{Imagen 1. Captura tuit del perfil de la cuenta Ministerio de Asuntos Exteriores, UE y Cooperación}

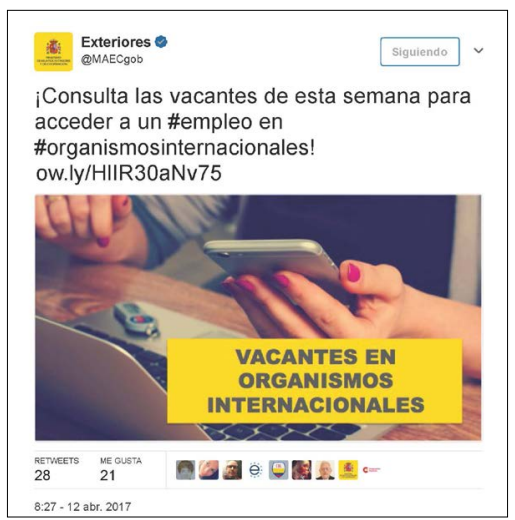

Fuente: https://twitter.com/MAECgob

Imagen 2. Captura tuit del perfil de la cuenta Ministerio de Cultura y Deporte

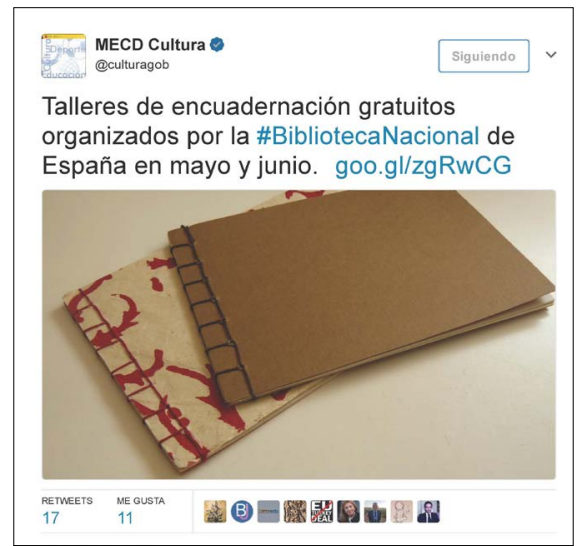

Fuente: https://twitter.com/culturagob

Las muestras consideran a estos tuits con interés en base a la información de utilidad que ofrecen. Son especialmente relevantes los tuits del Ministerio de Educación sobre convocatoria de becas, o los tuits del Ministerio de Administraciones Públicas por la oferta empleo público; los tuits de la Dirección General de Tráfico por recomendaciones para la movilidad; los tuits de la Policía 
Nacional y de la Guardia Civil por recomendaciones y alertas, y los de la Administración de Loterías y Apuestas por información de resultados, etc.

Los comentarios que se producen se centran en la relevancia de la información y/o la accesibilidad y propagación de dicha información que por lo general se considera de interés público, de ahí que sean bien valorados y que sean aparentemente más transparentes que otros tuits con menor interés o de menor utilidad informativa. El uso de estos tuits por la institución es constante y periódico, en buena parte programado e incluso inscrito en acciones de marketing, destinadas a la generación de usuarios específicos y sin esperas a que los ciudadanos soliciten dicha información. Dentro de los mensajes relativamente habituales se encuentran las instrucciones relativas a comportamientos de su ámbito de actividad. Informaciones sobre el qué hacer en caso de... o cómo presentar una determinada solicitud o semejante.

\section{Tuits visibles}

En esta categoría se incluyen algunos tuits como los del Ministerio de Hacienda, o los de Fomento cuando aportan información de actualidad y/o notorias por diversos motivos. Un ejemplo serían las siguientes actuaciones:

Imagen 3. Captura tuit (y comentarios) del perfil de la cuenta Ministerio del Interior

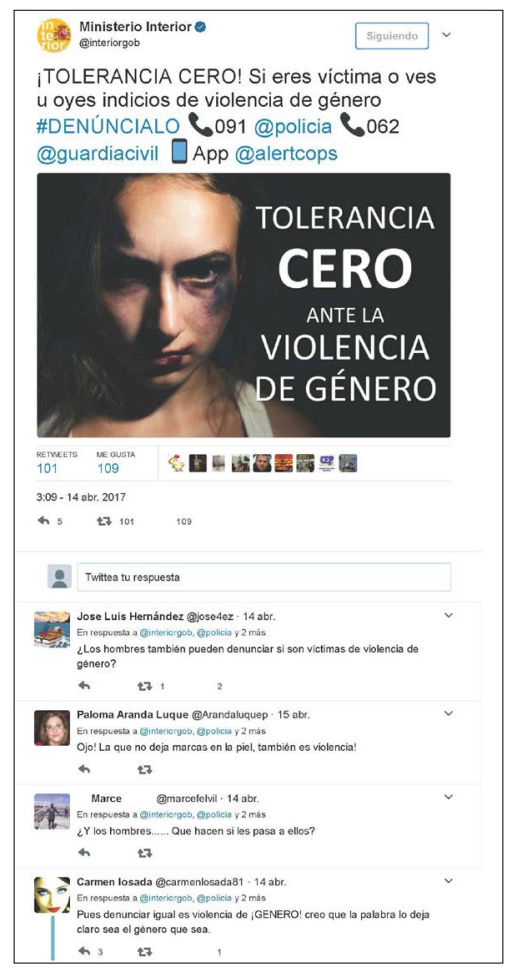

Fuente: https://twitter.com/interiorgob 
Imagen 4. Captura tuit (y comentarios) del perfil de la cuenta Ministerio Defensa

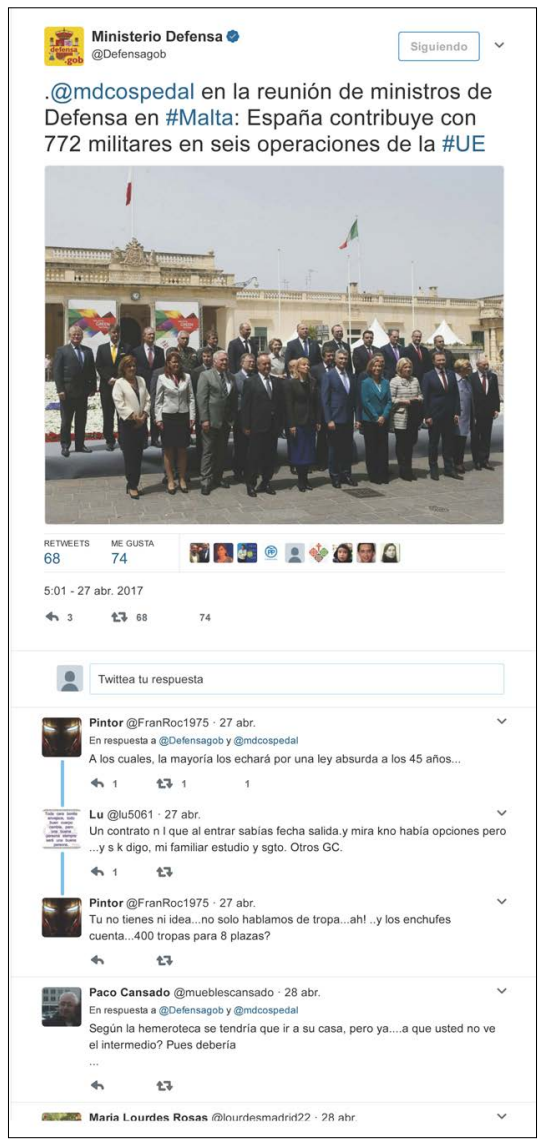

Fuente: https://twitter.com/Defensagob

Las respuestas que producen buscan aquilatar y/o comentar la información que se ofrece a través de la misma red, ya sea criticando los mensajes o apostillando observaciones adicionales (a veces irónicas) sobre la fuente de procedencia, los asuntos tratados, la recepción de los mensajes, etc. Desde este punto de vista, hay que señalar que los tuits provocadores despiertan en las muestras cierto interés general, aunque en algunos casos los mensajes no tengan mayor relevancia informativa ni ofrezcan aporte alguno desde un punto de vista práctico. En función del interés que producen las respuestas provocadas, es posible inferir el atractivo que despiertan y la facilidad para estimular la propagación de los mensajes, funcionando como mecanismo de descarga emocional y canalizando nueva información que pudiera estar implícita u oculta. Por otro lado, y a pesar de ser considerados tuits con información "supuestamente conocida" y hasta innecesaria en aras a dicho conocimiento, no por ello faltan a la 
transparencia, ya que se vincula la información que aportan los mismos receptores cuando comentan sus propias apreciaciones y contribuyen a la propagación.

Son tuits que promueven fundamentalmente la colaboración y/o implicación de los ciudadanos en los valores que pretende representar la institución que informa. En general se complementan con la actividad de las redes sociales y a partir de información que toca de lleno la vida cotidiana de los ciudadanos -por ejemplo, recordándoles medidas de seguridad, avisando de peligros o cumplimiento de deberes- o que les implica con asuntos que tienen una alta notoriedad o aceptación entre los ciudadanos (lucha contra violencia de género, oposición al maltrato animal o reconocimiento de la valía y valor de algunas personas, etc.).

\section{Tuits invisibles}

Por último, se menciona un conjunto de tuits que a juicio de las muestras "no aportan nada". No despiertan interés alguno y pasan totalmente desapercibidos. Son algunos tuits como los ofrecidos por el Ministerio de Defensa o el Ministerio de Medio Ambiente y del tipo siguiente:

\section{Imagen 5. Captura tuit del perfil de la cuenta Ministerio Defensa}

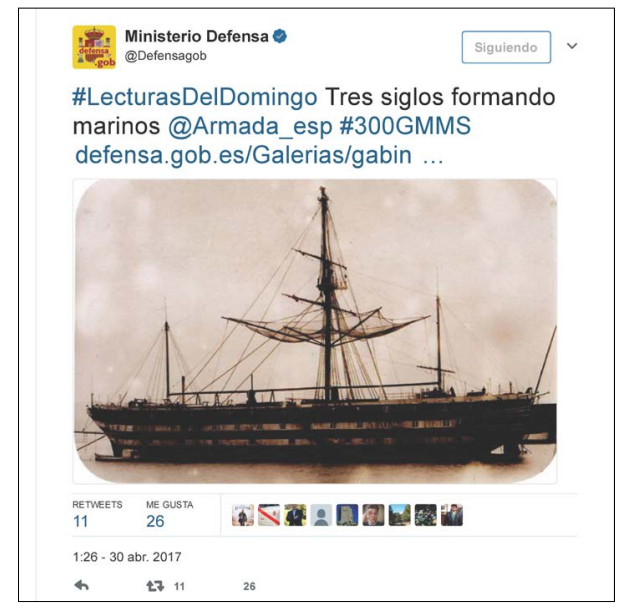

Fuente: https://twitter.com/Defensagob 


\section{Imagen 6. Captura tuit del perfil de la cuenta Ministerio Economía}

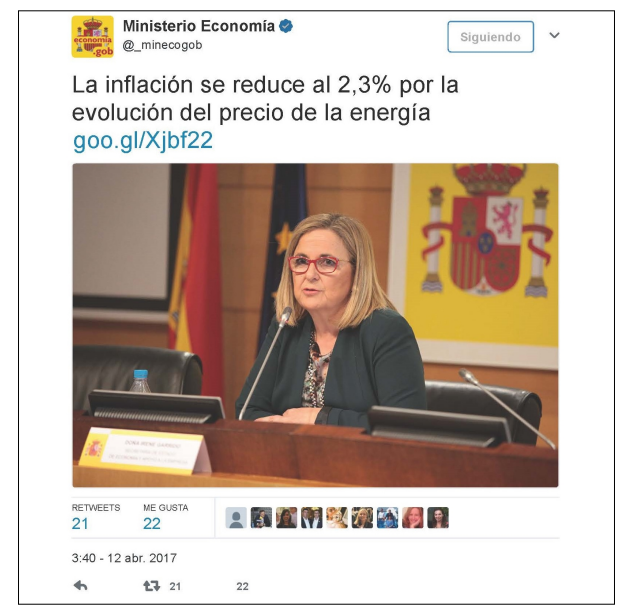

Fuente: https://twitter.com/_minecogob

Encontramos información que se entiende como publicidad institucional y con un bajo o nulo interés para las muestras. En ocasiones se compara con panfletos o propaganda sin gran atractivo, dejando claro que se trata de campañas destinadas a dar a conocer algún particular como una inauguración de unas obras públicas o la actividad rutinaria de un ministro, etc. En función del bajo interés que provocan y una manifiesta ausencia de intencionalidad en la información que declaran, los grupos tienden a obviar o denostar este tipo de tuits, considerando dicha falta de efectividad un motivo para dudar de su transparencia.

En general, puede decirse que la desafección por este tipo de tuits se vincula a la difusión del conocimiento de la institución y sus funciones entre los ciudadanos. Uno de sus usos frecuentes es responder a las preguntas realizadas por los ciudadanos sobre algún servicio concreto prestado por la institución o, en mayor medida, redireccionar a quienes consultan a los departamentos concretos que podrían tener la respuesta. Desde la perspectiva más estrictamente comunicativa, domina la función lingüística fática, consistente en manifestar que hay un canal abierto: las redes sociales digitales se configuran como un canal permanentemente abierto entre la institución y los ciudadanos. Ahora bien, los mensajes que se emiten desde la institución en ese canal suelen utilizar un lenguaje que podría considerarse plano desde el punto de vista emocional, muy formal y sin apenas personalización o cercanía, quedándose en lo que cabe denominar distancia burocrática. Cuentas dominadas por los anuncios o informaciones básicas.

En definitiva, estas tres categorías tratan de establecer formatos identificativos para clasificar distintos tuits en función de las respuestas globales y el carácter revelador de la información que ofrecen a los grupos analizados. En el siguiente epígrafe se presenta la incidencia que tiene dichas categorías de tuits para la observación de al menos cuatro tipos de transparencias para el receptor. 


\section{Tipos de transparencia informativa a través de los Social Media}

A partir de la categorización de tuits, y analizando en particular el papel que cobra la revelación de información y su grado de compartición, observamos en los grupos cuatro tipos de transparencias con referencia a los mensajes analizados.

A) Un primer tipo de transparencia pondría en conocimiento información revelada y compartida por quien la detenta (emisor). Se trata de una transparencia publicitaria o promocional ${ }^{8}$ centrada en propagar información y cuyo valor informativo puede ser muy limitado e incluso despreciable desde el punto de vista del receptor. En los grupos realizados se menciona el interés en dar a conocer y propagar cierta información independientemente de la relevancia o la existencia de una demanda que esté interesada en ella. Es una información que existe de oficio y que responde preferentemente al interés particular del informador. Los tuits referidos como "invisibles" son identificados en este sentido "publicitario" sin transcendencia, pero pueden a su vez generar la sospecha de ocultar información por ignorar el interés del emisor y por no reflejar el esfuerzo de transmisión debido al escaso interés que suscita dicha información etiquetada como muy distante, neutra y orientada a la institución que la emite. Los comentarios que suscita este tipo de transparencia son del tipo:

“H3: Es que es un poco ya, un poco como lo del tiempo, ¿no?

H1: Sí, es un poco fricada.

H3: “Aquí os traemos la foto del día por Roberto Álvarez de Barcelona," yo qué sé [risas]." (RG1).

b) Vinculado a este interés incierto para el receptor y muy especialmente a la ausencia del propósito transmisor, se observa una transparencia expositiva, que pone en conocimiento información revelada, pero sin expresa voluntad de propagarla activamente. Se trata de información que simplemente es "colgada" o expuesta (por ejemplo, la que se anuncia en la web, en un foro o en un boletín oficial) y no está necesariamente vinculada a la necesidad de transmitirla a un número creciente de individuos. Incluso es posible que la misma transparencia expositiva pueda interpretarse por los receptores como falta de interés en informar en la medida en que carece del interés o esfuerzo diseminador. Véase al respecto los siguientes comentarios:

“M1: Tendrían que poner mensajes más de "por Navidad, cien euros para todos de regalo", eso es lo que tendrían que poner.

M2: Ahí [risas].

M1: Eso estaría estupendo.

Moderador: Pero, por ejemplo, un mensaje como este...

M2: No, a ver...

Moderador: que dice "Venta directa de bienes, propiedades de la AGE, situados en Loeches, Madrid". Un mensaje como este...

M3: No". (RG2)

C) El mismo esfuerzo diseminador permite hablar a su vez de un tipo de transparencia transmisora que tiene por objeto la propagación como elemento central que contribuye a dar relevancia y contenido a la información revelada. Es decir, la infor-

8 Es de destacar el estudio de Gandía, Marrahí y Huguet (2015) sobre el uso de las herramientas propuestas por la Web 2.0 por parte de una muestra de ayuntamientos españoles. En sus conclusiones, destacan los autores que, aun cuando se gana algo en transparencia, el uso de las redes sociales online por parte de las instituciones municipales está casi restringido a un enfoque promocional. 
mación es propagada porque tiene interés (real o supuesto) para el receptor, y no sólo para la entidad emisora. Esta supuesta receptividad presupone a su vez incorporar una "transparencia del receptor", lo que lleva a ampliar el monto de información revelada y el sentido de la propagación al incluir a los receptores como parte de la información evidenciada. Los tuits referidos como "visibles" se identifican en parte con este tipo de transparencia transmisora, centrada en la diseminación como elemento clave para transmitir información de supuesto interés. Las emergencias, los avisos o advertencias son ejemplos de información considerada de interés para la ciudadanía en general, además de garantizar la propagación entre particulares y su efecto transmisor.

“H1: porque muchas veces te hacen un pantallazo del tipo de página o correo electrónico para que tú lo puedas identificar. Ahí sí lo veo correcto porque es una complementación a la propia información. Es decir, el ministerio, o sea, "el Cuerpo Nacional de Policía advierte de la nueva estafa que consiste en obtener número de cuenta a través de tal correo electrónico". Entonces te ponen un pantallazo del correo, que luego te pone "censurado" o lo que sea por el propio Cuerpo Nacional de Policía para que tú lo identifiques bien. Ahí sí que me parece complementario y necesario" (RG1).

D) Por último, existe una transparencia que se ve afectada por las limitaciones o incongruencias de la revelación (emisión), pero no por la propagación que es activa y consecuente con dichas limitaciones. Una transparencia que participa de la mirada y no sólo de la visión (demostración). En este caso lo que se propaga y comparte realmente son las interpretaciones y/o sospechas sobre aquello que no es revelado desde el punto de vista emisor ${ }^{9}$. En términos visuales, la transparencia referida muestra información que el receptor juzga inesperada y/ o "chirriante" al demandar ser vista desde una perspectiva más completa y/o con mayor coherencia. Esta defectuosa voluntariedad en la revelación de la información con miras a la transparencia genera un tipo especial de conocimiento informativo que tiene como función:

1.- Completar imaginariamente las revelaciones parciales o restringidas que son tratadas por el receptor como inquietantes y necesitadas de aporte informacional para su consideración. En las muestras observadas se comenta este déficit de información que es rápidamente recuperado por el lado de proyectar supuestos o sospechas que pueden ser o no falsas.

2.- Trasladar la revelación fuera del lugar donde opera la transparencia, es decir, haciendo que recaiga en el sujeto que la demanda (receptor). Paradójicamente, existe un esfuerzo del ciudadano (usuario) por producir transparencia en la medida en que dicha transparencia es limitada o adolece de incoherencia desde su particular punto de vista.

Como contra partida a la no voluntariedad de revelar (o revelar defectuosamente desde el punto de vista emisor) se produce, por tanto, un tipo de transparencia verosímil que informa a través de medios de comunicación interactivos y a través de los usuarios que demandan cierta información. Dicha transparencia queda fuera del alcance de la voluntad de revelar y, por tanto, del control que detenta el emisor sobre su propia información revelada. El siguiente extracto pone de relieve la doble condición que adquiere la transparencia informativa cuando genera inquietud en la recepción:

Moderador: Esta también es del Ministerio de Fomento. ¿Esta qué os parece? La de “Espectacular panorámica.... El que un ministerio publique, haga llegar este mensaje, este tuit o este mensaje, ¿qué os parece? "Espectacular panorámica de este faro, en ruta, Semana Santa. ¿Dónde se ubica?"

9 Precisamente, la teoría simmeliana acierta a señalar, y no sin motivos sobrados, que el trato entre los hombres descansa indefectiblemente en que cada uno sabe del otro algo más de lo que el otro le revela voluntariamente.

116 | n³4, pp. 103-120 | doxa.comunicación

enero-junio de 2022 
M1: De estas fotos hay muchas, no solo del Ministerio de Fomento, de otras páginas de viajes y de cosas que te dicen "mira este lugar" y te sale una foto maravillosa.

M2: [risas] ¿Ves? los comentarios, los comentarios.

M1: Los comentarios es lo más maravilloso.

M2: Sí, sí, sí.

M4: En Suiza [risas].

M2: Es muy bueno, ese es buenísimo, ese comentario. Es que se lo buscan ellos, si es que..., es que se lo buscan “. (RG3)

Efectivamente, los tuits "visibles" son los que dan pie a una mayor transparencia verosímil en el sentido de generar polémica y notoriedad debido al contexto acogedor que encuentran en las redes sociales y los "trend topic".

Al margen de este último tipo de transparencia constatada, y desde un punto de vista teórico, es sabido que cualquier información que se revela produce a su vez e indefectiblemente un monto de información no revelada y el correspondiente conocimiento proyectado (imaginado) que trata de informar sobre lo que supuestamente se deja de desvelar. Se trata de un juego que no tiene fin y que promueve el mismo hecho comunicativo como efecto de la transparencia generada, provocando a su vez nuevo vínculo social y deseo de más información y/o conocimiento.

La transparencia verosímil es, por tanto, una forma de propagar información a partir del mismo hecho comunicativo y en la media en que no cumple cabalmente con la revelación de la información demandada (y en cierta medida comunicada). En cuanto la información mostrada incluye un significante fuera de lugar (fuera de la escena en la que adquiere significado) y el receptor se ve obligado a crear un sentido (metafórico) o asumir el doble sentido con el que completar la información que demanda. De repente, todo lo mostrado por el emisor parece contener algún significado oculto o inadvertido que debe ser interpretado por el receptor.

Por otro lado, la misma potencialidad de los social media se considera ambivalente y/o limitada. Son valorados muy positivamente en cuanto instrumento para compartir y contactar sin limitación alguna, pero también se ven negativamente al incluir la revelación y la falta de control y seguimiento de la información compartida. Es por este motivo que las muestras mencionen repetidamente que dicha revelación sin control es incluso mayor de la que sospechan, generando en ocasiones prácticas para asegurarse frente al medio y/o aceptando la revelación dudosa como "pago" por el uso del medio.

En cualquier caso, parece evidente que los social media aparecen en las muestras como un medio acorde y consecuente con el fenómeno de la transparencia, ya que cumple sobradamente con el objetivo de revelar y propagar información en todos los sentidos. Por un lado, aportan e incentivan indefinidamente la relación social en la comunicación compartida sin niveles ni reservas. Por otro lado, generan aportes de información selectivos que tienen como finalidad activar y replicar sin límites la ampliación y propagación de información. 


\section{Conclusión}

Se ha llevado a cabo un estudio exploratorio sobre la transparencia informativa en los social media con el fin de conocer su alcance comunicativo y de cara a la participación ciudadana en la vida política. De los grupos realizados y analizados para tal efecto se destaca:

1.- Que la recepción de la información es una dimensión aparte e independiente de la estancia emisora, y que dicha distinción afecta y sobrepasa la estrecha concepción de una transparencia limitada a estándares y procedimientos dependiente exclusivamente de instancias emisoras.

2.- Que la idea genérica en la que se relaciona accesibilidad a la información con transparencia efectiva es como mínimo dudosa a partir de una transparencia recepcionada. Tanto es así que, a pesar de dicha vinculación, se pone de manifiesto que la accesibilidad no parece ser un elemento clave ni definitivo para justificar la pretendida transparencia. Es más, es evidente que el aporte de información gratuita puede ser objeto de falta de transparencia tal como demuestran comunicaciones sin notoriedad y/o ajenas a los intereses puntuales del receptor.

3.- De los cuatro tipos de transparencias resultantes a partir del análisis de los grupos (transparencia publicitaria, expositiva, transmisora y verosímil), la transparencia verosímil es la que demanda al emisor un mayor requerimiento de información producto de la importancia que cobra la limitada información revelada para el receptor. Es decir, que es el receptor en esencia quien completa y revela información al margen de la entidad emisora, lo que en cierta forma modula (y compensa) la supuesta capacidad de información que reciben los ciudadanos a través de medios de comunicación interactivos como los social media. En cualquier caso, habría que determinar en un futuro estudio la mayor o menor adecuación y funcionamiento de este tipo de transparencia verosímil en términos comparativos ${ }^{10}$.

Tabla 1. Tipos de transparencia informativa según fuente emisora y receptora

\begin{tabular}{|c|c|c|c|}
\hline \multicolumn{2}{|c|}{ TIPOS DE TRANSPARENCIA INFORMATIVA } & \multicolumn{2}{c|}{ APORTE INFORMACIONAL DEL RECEPTOR } \\
\cline { 3 - 4 } & & SI & NO \\
\hline \multirow{2}{*}{ APORTE INFORMACIONAL DEL EMISOR } & SI & Transmisora & Publicitaria \\
\cline { 2 - 4 } & NO & Verosímil & Expositiva \\
\hline
\end{tabular}

Fuente: elaboración propia

Sin perder de vista la tipología reseñada en este estudio, hay que señalar estudios que, centrados en esa política de la Open Government Initiative del Presidente Obama, han destacado la confusa relación entre percepción de transparencia y uso de las redes sociales (Unsworth y Townes, 2012). Es más, la mayor parte de los trabajos terminan demandando una gestión de las redes sociales por parte de las instituciones públicas más promotoras de la participación y la interactividad con los ciudadanos y, de esta forma, más transparente; algo que solo parece alcanzarse en aquellas agencias, organizaciones públicas o ramas institucionales encargadas de implementar directamente programas de actuación (Bekkers, Edwards y Kool, 2013).

10 A pesar del alcance limitado del estudio a partir del tiempo transcurrido, no se descarta posibles cambios fruto de las circunstancias especiales que puedan aparecer en el futuro, especialmente a raíz de acontecimientos recientes como la pandemia declarada en el 2020, y que podría dar lugar a revisar los resultados de esta investigación a la luz de la posible influencia que hayan tenido las redes sociales en la gestión e información de la pandemia.

118 | n 34, pp. 103-120 | doxa.comunicación

enero-junio de 2022 
En definitiva, para el caso español, una de las columnas vertebrales de Ley 19/2013, de Transparencia, Acceso a la Información Pública y Buen Gobierno es la obligación de publicar lo que se extiende por, al menos, dos dimensiones. Por un lado, el hacer públicas -publicar o hacer accesible- informaciones sobre el quehacer de la Administración. Pero, por otro lado, y no menos importante, la de hacer llegar al público, en su máxima extensión, tales informaciones o la posibilidad de acceder a ellas. En este segundo aspecto es donde las redes sociales pueden jugar un papel relevante, dada su amplia difusión entre los ciudadanos y su participación (implicación) en la producción de la transparencia en su conjunto.

\section{Agradecimientos}

Agradecemos al traductor Paul Cassidy la supervisión y traducción de este artículo al inglés.

\section{Referencias bibliográficas}

Austin, R.D. y Upton, D.M. (2016). Leading in the Age of Super-Transparency. MIT Sloan Management Review, 57 (2), 25 -34.

Backus, M. (2001). E-Governance in Developing Countries. IICD Research Brief. https://doi.org/10.1080/13600860410001674779

Bekkers, V., Edwards, A. y Kool, D. (2013). Social media monitoring: Responsive governance in the shadow of surveillance? Government Information Quarterly, 30 (4), 335-342.

Bentam, J. (1979). El panóptico. Editorial La piqueta.

Byung-Chul Han (2014). La sociedad de la transparencia. Herder.

Foucault, M. (1986). Vigilar y castigar. Siglo XXI Editores.

Fung, A. (2013). Infotopia: Unleashing the Democratic Power of Transparency. Politics \& Society 4 (2), 183-212.

Gil-García J. R. y Catarrivas, A. (2017). Enfoques Teóricos y Propuestas Metodológicas para el Estudio del Gobierno Digital. En Gil-García et al. (eds). Tecnologías de Información y Comunicación en la Administración Pública: Conceptos, Enfoques, Aplicaciones y Resultados. INFOTEC.

Hellman, J. y Kaufman, D. (2001). Confronting the Challenge of State Capture in Transition Economies. Finance \& Development, September, 38 (3). http://www.imf.org/external/pubs/ft/fandd/2001/09/hellman.htm

Kaufmann, D. y Siegelbaum, P. (1997). Privatization and Corruption in Transition Economies. Journal of International Affairs, 1997, 50 (2), 419-458.

Lacan, J., (1997), El Seminario Libro 11: Los Cuatro Conceptos Fundamentales del Psicoanálisis. Paidós.

Lathrop, D. y Ruma, L. (eds.) (2010). Open Government. Collaboration, Transparency, and Participation in Practice. O`Really Media.

Layne, K, y Lee, J. (2001). Developing Fully Functional E-government: A Four Stage Model. Government Information Quarterly 18 (2), 122-136.

Luhmann, N. (2000). La realidad de los medios de masas. Anthropos. 
McDermott, P. (2010). Building open government. Government Information Quarterly, 27, (4), 401-413.

Merleau-Ponty, M. (1986). El ojo y el espíritu. Paidós.

Simmel, G. (1906). The Sociology of Secrecy and of the Secret Societies. American Journal of Sociology, 11, 441-498.

Subirats, J. (2012). Nuevos tiempos, ¿nuevas políticas públicas? Explorando caminos de respuesta. Revista del CLAD Reforma y Democracia, 54, 5-32.

Unsworth, K. y Townes, A. (2012). Transparency, participation, cooperation: A case study evaluating Twitter as a social media interaction tool in the US open government initiative. ACM International Conference Proceeding Series, 90-96. https://doi. org/10.1145/2307729.2307745

Vattimo, G. (1989). La società trasparente. Garzanti.

Villoria M. y Ramírez, A. (2013). Los modelos de gobierno electrónico y sus fases de desarrollo: Un análisis desde la teoría política. Gestión y política pública, 22, 69-103.

Wajcman, G. (2010). El ojo absoluto. Manantial.

Zizek, S. (2000). Mirando al sesgo. Paidós. 